of local recurrence is three times that of ductal carcinoma.

The determination of those who selected mastectomy is interesting. In answer to the possible criticism that we may have influenced the patients to choose this treatment, we used a technique that biased the discussion towards conservation, which in the end was selected by fewer women. Bias towards conservation was also often applied by relatives and friends. Well meaning relatives may find it difficult to believe that mastectomy is genuinely the patient's choice. After a television news programme we received 20 telephone calls from relatives demanding to know why we were were not offering conservation to one of our patients, at whose choice mastectomy was due to be carried out the next morning. In the light of this we offered to postpone the operation but the patient asked us not to.

We have now started a two year prospective study of the impact of choice and its possible effects on anxiety and depression. We agree with the findings of a small study from Southampton that choice does not seem to cause harm, ${ }^{10}$ but we found that only a third of patients took up the offer of conservation treatment.

We conclude that women attending the breast clinic in this hospital are quite capable of playing a part in selecting their own primary treatment for operable breast cancer. Possibly patients with lobular cancers, which have a high rate of local recurrence, or in situ lesions, which are definitely cured by mastectomy, should not be offered conservation treatment. With the advent of screening programmes this poses a dilemma:
Should these patients be advised to have a mastectomy as it may offer a better chance of cure?

Overall, with two thirds of women choosing mastectomy and with mastectomy the best treatment for women with lobular lesions and cancers in situ it seems that less than $20 \%$ of women with early breast cancer will be suitable for conservation treatment. From the patients' point of view centres where conservation is available and there is enthusiasm for it should offer it as an alternative. Equally, they should make clear to the patients that a mastectomy is still an available option.

I Ashford RFU, Phillips RH, Coe MA, Pickering DGL, Bailey B, Ellis H. Conservation excision and radiotherapy for early breast cancer - an acceptable alternative? British fournal of Clinical Oncology 1984;10:45-58.

2 Nisar Syed AM, Ajmel AP, Orr LE, et al. Primary irradiation in the management of early and advanced carcinoma of the breast. Br 7 Radiol 1984;57:317-21.

3 Pierquin B, Owen R, Maylan C, et al. Radical radiation therapy for breast cancer. Int $\mathcal{A}$ Radiat Oncol Biol Phys 1980;6:17-24.

4 Fischer B, Baur M, Margolese R, et al. Five year results of a randomised clinical trial comparing total mastectomy and segmental mastectomy with or without radiotherapy in the treatment of breast cancer. $N$ Engl $\mathcal{F ~ M e d}$ 1985;312:665-73

5 Maguire P. The psychological impact of cancer. Br $\mathcal{F}$ Hosp Med 1985;34:100-3.

6 Fallowfield LJ, Baum M, Maguire GP. Effects of breast conservation on psychological morbidity associated with the diagnosis and treatment of early breast cancer. Br Med F 1986;293:1331-4.

7 Haimes A, Dawes PJDK, Wilson RG. Can women choose their own treatment for primary breast cancer? [Abstract.] British foumal of Clinical Oncology 1983;9:82.

8 Haimes A, Sterling E. Choice aids recovery. Nursing Times 1987 Feb 25:49-51.

9 Anonymous. Report of the international multicentre trial supported by the clinical research centre. Management of early cancer of the breast. Br Med $f$ clinical research

10 Morris J, Royle GT. Choice of surgery for early breast cancer: pre- and postoperative levels of clinical anxiety and depression in patients and their husbands. Br f Surg 1987;74:1017-9.

(Accepted 21 fuly 1988)

\title{
Relaxation and imagery in the treatment of breast cancer
}

\author{
Linda R Bridge, Pauline Benson, Patrick C Pietroni, Robert G Priest
}

\section{Abstract}

Objective-To see whether stress could be alleviated in patients being treated for early breast cancer.

Design-Controlled randomised trial lasting six weeks.

Setting-Outpatient radiotherapy department in a teaching hospital.

Patients-One hundred fifty four women with breast cancer stage I or II after first session of six week course of radiotherapy, of whom 15 dropped out before end of study.

Intervention-Patients saw one of two researchers once a week for six weeks. Controls were encouraged to talk about themselves; relaxation group was taught concentration on individual muscle groups; relaxation and imagery group was also taught to imagine peaceful scene of own choice to enhance relaxation. Relaxation and relaxation plus imagery groups were given tape recording repeating instructions and told to practise at least 15 minutes a day.

End point-Improvement of mood and of depression and anxiety on self rating scales.

Measurements and main results - Initial scores for profile of mood states and Leeds general scales for depression and anxiety were the same in all groups. At six weeks total mood disturbance score was significantly less in the intervention groups, women in the combined intervention group being more relaxed than those receiving relaxation training only; mood in the control group was worse. Women aged 55 and over benefited most. There was no difference in Leeds scores among the groups.
Conclusions-Patients with early breast cancer benefit from relaxation training.

\section{Introduction}

In an attempt to understand more about the aetiology of cancer several studies have investigated whether life stresses (often "loss" events) are among the psychological risk factors for the disease. Though some significant links have been reported, ${ }^{1-3}$ other studies have failed to show this relation. ${ }^{45}$ Doubts have been cast on the validity of linking life events and cancer, as the variations in growth rates of tumours make it difficult to establish whether any particular stressful event antedates the "biological" onset of cancer. ${ }^{6-8}$

As yet there appears to be no consistent evidence of a causal relation between life stresses and cancer, but it seems reasonable to suppose that the procedures of being diagnosed and treated for cancer are themselves stressful. ${ }^{9-11}$ Maguire suggested that "most of the mood disturbance which occurs in patients with cancer probably results from their inability to cope psychologically with the stresses caused by their disease and treatments. They face the threats that they may lose their health, role, and life. They also have to live with the uncertainty as to whether and when these losses will occur." 12

Patel and coworkers have shown that relaxation treatment reduces stress in hypertension. ${ }^{1314}$ Fleming found that relaxation treatment offered to patients with far advanced cancer seemed to benefit most those who were seen on an individual basis. ${ }^{15}$ Another study of
Correspondence and requests for reprints to: Professor Priest. 
patients with cancer showed that the systematic use of positive thought and imagery when patients were in a relaxed frame of mind helped prolong their lives. ${ }^{16}$

This study investigated ways of alleviating psychological stress in patients with diagnosed breast cancer, which is the commonest cancer and chief cause of death in women aged 35-54. ${ }^{17}$ (In 1984 there were 13000 deaths from breast cancer in England and Wales. ${ }^{18}$ ) We hypothesised that patients given either of two relaxation treatments would show a more positive effect on their mood states than a control group of similar, untreated women and that the group given relaxation training with an imagery component would show more change than women given relaxation training alone.

\section{Patients and method}

The sample was made up of a consecutive series of women who had been treated by either mastectomy or breast conservation for early breast cancer stages I and II - that is, as defined by the Union International Contra le Cancrum as tumours of $5 \mathrm{~cm}$ diameter or less with or without palpable axillary nodes and having no evidence of distant metastases. ${ }^{19}$ All the women were outpatients having a six week course of radiotherapy at the Middlesex Hospital, London; were under age 70; and could understand English. (Because the study period covered the six week period of radiotherapy, to avoid possible confusion we refer to the six week study programme as treatment.)

Initially 183 women fulfilled the study criteria but 22 $(12 \%)$ refused to partieipate. Informed consent was given by the remaining 161 , who were then allocated by means of a random numbers table to either a treatment or control condition. Seven of these had to be excluded after staging tests detected metastases, leaving 154 women. Of these, 15 dropped out before the end of the study (five assigned to the relaxation plus imagery group, six to relaxation only, and four to the control group). Thus 139 women completed the full treatment package.

Selection of methods of assessment was determined by the need to be non-intrusive and cause minimum disruption to the routine of patients attending for radiotherapy. The profile of mood states questionnaire $^{20-22}$ and the Leeds general scales for the self assessment of depression and anxiety ${ }^{23}$ were chosen, as they are self rating measures which have been used in patients with cancer. ${ }^{24}$ The profile of mood states uses 65 items to yield scores on subscales for tension, depression, vigour, fatigue, anger, and confusion. A total mood disturbance score is calculated from these scores and used as a global measure of dysphoric mood. The Leeds general scales measure the severity of depressive and anxiety symptoms in patients who have not received a primary diagnosis of affective illness. The scales contain six items each for depression and anxiety, all self rated on a four point scale. A score of 7 or more indicates the presence of either state. To minimise response set some items are scored negatively.

All the women had received at least one session of radiotherapy before being invited to join the study. They were told that a study was being carried out to investigate ways of alleviating stress during radiotherapy and that participants would be randomly allocated to one of three groups, about which full details were given. They would also be required to complete several questionnaires. We emphasised that agreement or refusal to join the study would not affect their course of radiotherapy, that no drugs would be given, nothing would appear in their medical records, and that confidentiality would be maintained throughout.

Patients completed a profile of mood states and
Leeds general scales questionnaire on entry to the study and again at the end of the six week treatment period. The 139 women in the study were seen individually by one of the two researchers once a week for the six weeks of their radiotherapy courses. The researchers were equally concerned in working with all three groups.

Both treatment groups (relaxation and relaxation plus imagery) were taught a relaxation technique which by a process of direct concentration focuses sensory awareness on a series of individual muscle groups. ${ }^{25}$ These patients were also given instructions for diaphragmatic breathing, which slows respiration, induces a calmer state, and reduces tension. ${ }^{26}$ In addition to the breathing and relaxation, each patient in the relaxation plus imagery group was taught to imagine a peaceful scene of her own choice as a means of enhancing the relaxation. ${ }^{27}$ Sessions lasted about half an hour. During this time the exercises were practised by the treatment groups, whereas the women in the control group were encouraged simply to talk about themselves and their interests.

All patients in the treatment groups were given a tape which repeated the breathing instructions and contained the relaxation or relaxation and imaging exercise. It was suggested to them that this should be practised at home for at least 15 minutes each day. (If required, tape recorders were available on loan for the duration of the study.)

Data analysis-Demographic variables were compared by the $\chi^{2}$ test. Initial scores on the profile of mood states and Leeds general scales were examined by analysis of variance. Relative changes in these scores were examined by analysis of covariance to control for the initial test score. ${ }^{28}$ All the tests were two tailed except when indicated.

\section{Results}

Table I gives details of the 139 women who completed the six week study programme. Forty seven were randomised to receive relaxation training, 44 to

TABLE I-Characteristics of patients in the three study groups. Except where stated otherwise figures are numbers of patients

\begin{tabular}{|c|c|c|c|}
\hline & $\begin{array}{c}\text { Relaxation } \\
\substack{(\mathrm{n}=47) \\
\text { roup }}\end{array}$ & $\begin{array}{l}\text { Relaxation } \\
\text { plus imagery } \\
\text { group } \\
(\mathrm{n}=44)\end{array}$ & $\begin{array}{c}\text { Controls } \\
(n=48)\end{array}$ \\
\hline & $51 \quad(10)$ & $53(11)$ & $54 \quad(10)$ \\
\hline Marital state: & & & \\
\hline Married/cohabiting & 37 & 30 & 38 \\
\hline Widowed/divorced/separated & 4 & 9 & 4 \\
\hline Never marr & 6 & 5 & 6 \\
\hline Social class: & & & \\
\hline I & 1 & 6 & 3 \\
\hline II & 20 & 5 & 13 \\
\hline IIIa & 11 & 9 & 12 \\
\hline IIIb & 6 & 4 & 8 \\
\hline IV & 6 & 15 & 10 \\
\hline $\mathrm{V}$ & 3 & 5 & 2 \\
\hline $\begin{array}{l}\text { Mean total mood disturbance score on } \\
\text { initial profile of mood states (SD) }\end{array}$ & $61 \cdot 7(31 \cdot 2)$ & $59 \cdot 6(34 \cdot 5)$ & $54 \cdot 4(26 \cdot 0)$ \\
\hline $\begin{array}{l}\text { Mean score on initial Leeds } \\
\text { general depression scale (SD) }\end{array}$ & $4 \cdot 3(2 \cdot 9)$ & $4.8(3.5)$ & $5 \cdot 1(3 \cdot 2)$ \\
\hline $\begin{array}{l}\text { Mean score on initial Leeds general } \\
\text { anxiety scale (SD) }\end{array}$ & $6 \cdot 0(4 \cdot 0)$ & $5 \cdot 7(4 \cdot 0)$ & $6.4(3.9)$ \\
\hline
\end{tabular}

receive relaxation plus imagery training, and 48 to serve as controls. Demographic variables and initial questionnaire scores were compared across the groups; no significant differences were found at the $5 \%$ level.

Twenty five women had received adjuvant chemotherapy at the time of or after operation before being recruited to the study. Their initial scores on the profile of mood states and Leeds general scales were compared with the scores of the 114 women who did not have adjuvant chemotherapy; no significant differences were found at the $5 \%$ level. 
Of all 139 patients studied, only 19 had had a mastectomy (reflecting the current shift towards breast conservation). When the sample was divided by type of surgery initial scores on the profile of mood states and Leeds general scales were similar for mood state and psychiatric morbidity.

The initial and six week scores on the profile of mood states and Leeds general scales were compared by analysis of covariance (controlling for initial scores) to test for the effects of treatment. Because it had been predicted that relaxation treatment would be better than no treatment (control) and that relaxation plus imagery would be better than relaxation alone the linear polynomial trend for treatment effects was calculated. There were no significant differences on the Leeds general scales but the total mood disturbance score on the profile of mood states differed significantly in the predicted way $(p<0.05$, one tailed; table II). This indicated that relaxation positively affected mood state and that this positive effect was further enhanced when relaxation was combined with imagery.

Though none of the subscales of the profile of mood states showed a statistically significant difference among the three groups of patients, all the relative changes over the treatment period were in the predicted direction (except for the vigour subscale, where relaxation was superior to relaxation plus imagery).

The item "relaxed" is part of the subscale for tension in the profile of mood states, and relaxation training was a main component of the treatment package. Interestingly, therefore, at the end of the study period analysis of covariance showed that the women trained in relaxation plus imagery were more relaxed than those trained in relaxation only, who in turn were more relaxed than the controls $(p<0.025$, one tailed), as judged by scores for this item.

Before examining the data we had decided to divide

TABLE II-Mean scores on profile of mood states at beginning and end of treatment (SD in parentheses)

\begin{tabular}{|c|c|c|c|c|}
\hline Profile of mood states & $\begin{array}{l}\text { Relaxation } \\
\text { group } \\
(\mathrm{n}=39)\end{array}$ & $\begin{array}{l}\text { Relaxation } \\
\text { plus imagery } \\
\text { group } \\
(n=43)\end{array}$ & $\begin{array}{c}\text { Controls } \\
(n=46)\end{array}$ & $\begin{array}{c}\mathrm{p} \text { Value } \\
\text { (one } \\
\text { tailed) }\end{array}$ \\
\hline \multicolumn{5}{|l|}{ Tension: } \\
\hline Initial & $11 \cdot 2(7 \cdot 0)$ & $11 \cdot 3(7 \cdot 9)$ & $10 \cdot 6(7 \cdot 0)$ & \\
\hline Six weeks & $9 \cdot 5(7 \cdot 7)$ & $8.8(5 \cdot 0)$ & $10 \cdot 7(8 \cdot 1)$ & 0.043 \\
\hline \multicolumn{5}{|l|}{ Depression: } \\
\hline Initial & $7 \cdot 4(7 \cdot 2)$ & $8 \cdot 3(9 \cdot 2)$ & $5 \cdot 5(6 \cdot 5)$ & \\
\hline Six weeks & $6.9(8.5)$ & $5 \cdot 8(5 \cdot 2)$ & $7 \cdot 5(10 \cdot 8)$ & 0.023 \\
\hline \multicolumn{5}{|l|}{ Vigour: } \\
\hline Initial & $18 \cdot 5(7 \cdot 5)$ & $16 \cdot 6(7 \cdot 7)$ & $17 \cdot 3(6 \cdot 6)$ & \\
\hline Six weeks & $18.5(6.3)$ & $17 \cdot 4(8 \cdot 3)$ & $18.9(7.9)$ & $0 \cdot 254$ \\
\hline \multicolumn{5}{|c|}{ 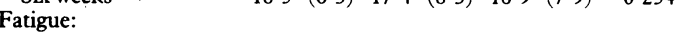 } \\
\hline Initial & $9 \cdot 2(8 \cdot 1)$ & $8 \cdot 7(7 \cdot 1)$ & $8 \cdot 7(6.5)$ & \\
\hline Six weeks & $11.9(8.5)$ & $10.4(8.0)$ & $11.9(8.0)$ & $0 \cdot 152$ \\
\hline \multicolumn{5}{|c|}{ 2. } \\
\hline Initial & $7.9(6.0)$ & $7 \cdot 8(6.9)$ & $5 \cdot 6(5 \cdot 2)$ & \\
\hline Six weeks & $7 \cdot 8(8 \cdot 3)$ & $5 \cdot 9(4 \cdot 4)$ & $5 \cdot 5(6 \cdot 4)$ & $0 \cdot 149$ \\
\hline \multicolumn{5}{|l|}{ Confusion: } \\
\hline Initial & $7.5(4.9)$ & $6.8(5.4)$ & $6 \cdot 8(4 \cdot 2)$ & \\
\hline Six weeks & $7 \cdot 3(5 \cdot 0)$ & $5 \cdot 7(4 \cdot 1)$ & $7 \cdot 0(5 \cdot 2)$ & 0.066 \\
\hline \multicolumn{5}{|l|}{ Total mood disturbance: } \\
\hline Initial & $61 \cdot 7(31 \cdot 2)$ & $59 \cdot 6(34 \cdot 5)$ & $54 \cdot 4(26 \cdot 0)$ & \\
\hline Six weeks & $61 \cdot 9(34.8)$ & $53.9(27 \cdot 4)$ & $61 \cdot 4(38 \cdot 7)$ & 0.036 \\
\hline
\end{tabular}

$\star$ For linear trend in analysis of covariance, controlling for initial scores.

TABLE III-Mean scores on profile of mood states at end of treatment in the three study groups stratified by age

\begin{tabular}{|c|c|c|c|c|c|c|c|}
\hline \multirow[b]{2}{*}{$\begin{array}{l}\text { Profile of } \\
\text { mood states }\end{array}$} & \multicolumn{2}{|c|}{$\begin{array}{l}\text { Relaxation } \\
\text { group }\end{array}$} & \multicolumn{2}{|c|}{$\begin{array}{l}\text { Relaxation plus } \\
\text { imagery group }\end{array}$} & \multicolumn{2}{|c|}{ Controls } & \multirow[b]{2}{*}{ p Value } \\
\hline & $\begin{array}{c}\text { Age }<55 \\
(\mathrm{n}=29)\end{array}$ & $\begin{array}{c}\text { Age } \geqslant 55 \\
(n=15)\end{array}$ & $\begin{array}{c}\text { Age }<55 \\
(\mathrm{n}=17)\end{array}$ & $\begin{array}{c}\text { Age } \geqslant 55 \\
(\mathrm{n}=23)\end{array}$ & $\begin{array}{c}\text { Age }<55 \\
(\mathrm{n}=22)\end{array}$ & $\begin{array}{c}\text { Age } \geqslant 55 \\
(n=24)\end{array}$ & \\
\hline Tension & $9 \cdot 1$ & $10 \cdot 3$ & $9 \cdot 4$ & 8.4 & $7 \cdot 9$ & $13 \cdot 2$ & 0.018 \\
\hline Depression & $6 \cdot 6$ & $7 \cdot(\cdot$ & 6.6 & $5 \cdot 2$ & $4 \cdot 1$ & 10 & 0.002 \\
\hline Vigour & $18 \cdot 0$ & $19 \cdot 4$ & $20 \cdot 5$ & $15 \cdot 0$ & $17 \cdot 7$ & $20 \cdot 0$ & 0.068 \\
\hline Fatigue & $12 \cdot 6$ & $10 \cdot 6$ & $13 \cdot 7$ & $7 \cdot 9$ & $10 \cdot 9$ & $12 \cdot 8$ & 0.095 \\
\hline Anger & $8 \cdot 8$ & 5.9 & 6.9 & $5 \cdot 1$ & $4 \cdot 9$ & $6 \cdot 0$ & 0.391 \\
\hline Confusion & $7 \cdot 3$ & $7 \cdot 1$ & $6 \cdot 1$ & $5 \cdot 4$ & $5 \cdot 6$ & $8 \cdot 3$ & $0 \cdot 105$ \\
\hline Total mood disturbance & $62 \cdot 3$ & $60 \cdot 9$ & $63 \cdot 1$ & $47 \cdot 0$ & $51 \cdot 0$ & $71 \cdot 0$ & 0.005 \\
\hline
\end{tabular}

*Analysis of covariance, controlling for initial scores. the sample by age and compare the effect of treatment in younger and older women. The cut point was the median age - that is, 54 . On the divided sample the interaction between age and treatment was found to be significant in the profile of mood states for tension $(\mathrm{p}<0.025)$, depression $(\mathrm{p}<0.005)$, and total mood disturbance $(p<0.005)$ (table III). This showed that relaxation and relaxation plus imagery particularly helped the overall mood state of the older women by reducing tension and depression relative to that of the controls and that the relaxation plus imagery treatment group showed the most effect. Another finding was that women aged 55 and older were less likely to work during the six weeks of radiotherapy than the younger women $\left(\chi^{2}=12.62 ; \mathrm{df}=1 ; \mathrm{p}<0.001\right)$. No differences were found in the Leeds general scales when the sample was divided by age.

To see whether anger and treatment were related those women with initial scores for anger in the lower quartile in the profile of mood states $(n=30$; scores $0-2$, mean 0.93 ) were compared with the rest of the sample $(n=98$; scores $3-31$, mean $9 \cdot 20)$. There were no significant differences in scores on the profile of mood states or Leeds general scales at the end of the treatment period. Those women with initial anger scores in the upper quartile in the profile of mood states $(n=35$; scores 10-31, mean 15.29) were compared with the others in the sample ( $n=93$; scores $0-9$, mean $4 \cdot 24)$. Analysis of covariance showed that the women with high scores for anger who were in the relaxation and relaxation plus imagery groups were less vigorous $(\mathrm{p}<0.05)$, more fatigued $(\mathrm{p}<0.05)$, and, with exclusion of the anger component, had greater total mood disturbance $(\mathrm{p}<0.025)$.

\section{Discussion}

The question that we set out to answer was whether relaxation and relaxation plus imagery were effective ways of reducing stress in a group of patients with early breast cancer who were attending as hospital outpatients for radiotherapy. When mood state and morbidity during radiation treatment were studied by Peck and Boland they found that anxiety increased at the end of a course of radiotherapy. ${ }^{29}$ They suggested that this was because reactions to radiation, both systemic and local, were then at their peak, adding to the distress which existed before treatment. Forester $e t$ al claimed that people may experience a decrease in dysphoric mood during radiotherapy because this is when they feel that something is being done about their illness and they are receiving attention..$^{30}$

In view of these suggestions we should have expected increased scores at the end of radiotherapy for all the patients in our study. In fact, our results on the profile of mood states scale showed that at the end of the treatment period for the cohort as a whole not only had overall mood state improved most in the relaxation plus imagery group, followed by the relaxation group, but also that the overall mood state of the women in the untreated group had become worse. As hypothesised, relaxation plus imagery had a more positive effect on mood state than relaxation only, and both treatment programmes were more effective than no treatment. On examining the characteristics of the groups we doubt that the results of treatment can be explained on the basis of the initial selection.

Why was relaxation plus imagery more effective than relaxation alone? The simplicity of the imagery, suggesting a peaceful, pleasant scene of the patient's choice, meant that it was within everyone's grasp. Often the image made the patient smile, at a time when smiles were perhaps few and far between. The pleasant scene could be recalled easily at any time, and the researchers emphasised that it was a resource which 
every person had within them. By contrast, the more aggressive style of imaging, which aims at strengthening the immune system by visualising the symbolic destruction of cancer cells, ${ }^{31}$ may bring about a sense of failure and helplessness if this desired result does not subsequently occur.

Both types of treatment used in this study were shown to be more effective in women aged 55 or over, who showed less tension and depression at the end of the six weeks as well as more improvement on overall mood state. Why did the older women respond better to treatment? As mentioned above, substantially fewer of these women worked during their course of radiotherapy. Because of their age they would be less likely to have children to care for and possibly led less busy lives than the younger women. Thus it may be that the older women had more time to practise our treatment programme.

Several studies of cancer have focused on abnormal release of anger, suggesting that both extreme suppression and extreme expression of anger may be characteristic of patients with cancer. ${ }^{32}{ }^{33}$ In this study we found no differences in the profile of mood states or Leeds general scales at the end of the treatment period for women with low anger scores-that is, extreme suppression-but we found that women with high anger scores who received relaxation or relaxation plus imagery treatment showed more fatigue, less vigour, and greater total mood disturbance than the controls. It may be that some women are so angry that they are unable to derive any benefit from relaxation treatment. We do not know whether before diagnosis those women with high scores for anger had always expressed their anger. Possibly they had been accustomed to suppressing anger and the knowledge that they had cancer gave them a legitimate reason for displaying it. Peck found that almost half of his sample of 50 patients displayed extreme anger in response to their cancer. ${ }^{9}$ We hope that future work will clarify this point.

Other studies have found a high prevalence of psychiatric morbidity in patients with mastectomy given adjuvant chemotherapy..$^{24}{ }^{34}$ We cannot address this issue, as only one of the 19 patients with mastectomy in our study had received adjuvant chemotherapy.

The Leeds general scales for anxiety and depression showed no significant changes over the six weeks of treatment. This may be because the scales contain certain somatic items - for example, disturbed sleep and appetite - which may have a physical cause and be less sensitive than psychological items to change in response to relaxation treatment. The hospital anxiety and depression scale, ${ }^{35}$ which omits somatic items, is currently being used to assess psychiatric morbidity in patients with cancer ${ }^{36}$ and may prove to be a better measure for use in work in this subject.

Sims, in her review of published work relating to relaxation techniques and patients with cancer, criticised studies which did not identify the sample population, had insufficient numbers, grouped all patients with cancer together as if they were a homogeneous group, and failed to control for attention by instructors. $^{37}$ Our study addressed these issues and showed that easily learnt relaxation treatments significantly improved the mood state of patients receiving a course of radiotherapy for early breast cancer, that relaxation plus imagery was the most effective treatment, and that women aged 55 and over benefited most.

This study was conceived and initiated by Betsy Little and funded by the Cancer Research Campaign. We thank Professor M Baum, of the Cancer Research Campaign Clinical Trials Centre, for monitoring clinical state. We are also indebted to Charlie Owen for statistical advice, Dawn Beaumont for computer programming, Lucy Albu for clerical work, and the staff and patients of the Middlesex Hospital's radiotherapy department for their support and cooperation.

1 Snow H. Cancer and the cancer process. London: J and A Churchill, 1893.

2 LeShan L, Worthington RE. Personality as a factor in the pathogenesis of cancer. Br $\mathcal{F}$ Med Psychol 1956;29:49-56.

3 Jacobs TJ, Charles E. Life events and the occurrence of cancer in children. Psychosom Med 1980;42:11-24.

4 Schonfield J. Psychological and life-experience differences between Israeli women with benign and cancerous breast lesions. I Psychosom Res 1975;19:229-34.

5 Greer S, Morris T. The study of psychological factors in breast cancer: problems of method. Soc Sci Med 1978;12:129-34.

6 Cox T, Mackay C. Psychosocial factors and psychophysiological mechanisms in the aetiology and development of cancers. Soc Sci Med 1982;16:381-96. in the aetiology and development of cancers. Soc Sci Med 1982;16;
Greer S. Cancer and the mind. Br $\mathcal{F}$ Psychiatry 1983;143:535-43.

7 Greer S. Cancer and the mind. Br $\mathcal{F}$ Psychiatry 1983;143:535-43.

9 Peck A. Emotional reactions to having cancer. American fourmal of Roentgeno logy, Radium Therapy, and Nuclear Medicine 1972;114:591-9.

10 Greer S, Silberfarb PM. Psychological concomitants of cancer. Psychol Med 1982;12:563-73.

11 Maguire P. Psychological reactions to breast cancer and its treatment. In Bonadonne G, ed. Breast cancer: diagnosis and management. Chichester: John Wiley and Sons, 1984:303-18.

12 Maguire P. Psychological and social consequences of cancer. In: Williams CJ, Whitehouse JWA, eds. Recent advances in clinical oncology. London: Churchill Livingstone, 1981:376.

13 Patel C, Marmot MG, Terry DJ. Controlled trial of biofeedback-aided behavioural methods in reducing mild hypertension. Br Med $\mathcal{F} 1981 ; 282$. 2005-8.

14 Patel C. Trial of relaxation in reducing coronary risk: four year follow up. $\mathrm{Br}$ Med f 1985;290:1103-6.

15 Fleming U. Relaxation therapy for far-advanced cancer. Practitioner 1985;229: 471-5.

16 Simonton O, Simonton S. Belief systems and management of the emotional aspects of malignancy. Transpersonal Psychology 1975;7:29-47.

17 Consensus Development Conference Panel. Treatment of primary breas cancer. Br Med F 1986;293:946-7.

18 Office of Population Censuses and Surveys. Mortality statistics, 1984. Ser DH2. No 11. London: HMSO, 1985.

19 Union International Contra le Cancrum. TNM classification of malignant tumours. Geneva: UICC, 1974

20 McNair DM, Lorr M, Droppleman LF. Profile of mood states manual. California: Educational and Industrial Testing Service, 1971. (Available from NFER-Nelson, Windsor, Berkshire.)

21 Worden JW, Sobel HJ. Ego strength and psychosocial adaptation to cancer. Psychosom Med 1978;40:85-92.

22 Spiegel D, Bloom JR, Yalom I. Group support for patients with metastatic cancer. Arch Gen Psychiatry 1981;38:527-33.

23 Snaith RF, Bridge GWK, Hamilton $M$. The Leeds scales for the self assessment of anxiety and depression. Brf Psychiatry 1976;128:156-65.

24 Cooper AF, McArdle CS, Russell AR, Smith DC. Psychiatric morbidity associated with adjuvant chemotherapy following mastectomy for breas cancer. Brf Surg 1979;66:362.

25 McLean J. The use of relaxation techniques in general practice. Practitioner 1986;230:1079-84.

26 Everly GS, Rosenfeld R. The nature and treatment of the stress response. New York: Plenum, 1981:131-41.

27 Lyles JN, Burish TG, Krozely MG, Oldham RK. Efficacy of relaxation training and guided imagery in reducing the aversiveness of cancer chemotherapy. F Consult Clin Psychol 1982;50:509-24.

28 Plewis I. Analysing change. London: John Wiley and Sons, 1985.

29 Peck A, Boland J. Emotional reactions to radiation treatment. Cancer 1977;40:180-4.

30 Forester BM, Kornfeld DS, Fleiss J. Psychiatric aspects of radiotherapy. Am $\mathcal{f}$ Psychiatry 1978;135:960-3.

31 Simonton O, Simonton S, Creighton J. Getting well again. Los Angeles: JP Tarcher, 1978.

32 Greer S, Morris T. Psychological attributes of women who develop breast cancer: a controlled study. I Psychosom Res 1975;19:147-53.

33 Jansen MA, Muenz LR. A retrospective study of personality variables associated with fibrocystic disease and breast cancer. I Psychosom Res 1984;28:35-42.

34 Maguire GP, Tait A, Brooke M, Thomas C, Howat JMT, Sellwood RA Psychiatric morbidity and physical toxicity associated with adjuvan chemotherapy after mastectomy. Br Med f 1980;281:1179-80.

35 Zigmund AS, Snaith RP. The hospital anxiety and depression scale. Acto Psychiatr Scand 1983;67:361-70.

36 Fallowfield LJ, Baum M, Maguire GP. Effects of breast conservation on psychological morbidity associated with diagnosis and treatment of early psychological morbidity associated with
breast cancer. Br Med f 1986;293:1331-4.

37 Sims SER. Relaxation training as a technique for helping patients cope with the experience of cancer: a selective review of the literature. $\mathcal{J}$ Adv Nurs 1987;12:583-91.

(Accepted 28 fuly 1988)

\section{Correction}

\section{Fluorescent lights, ultraviolet lamps, and risk of cutaneous melanoma}

We regret that three errors occurred in this paper by $\operatorname{Dr} \mathrm{A} \mathrm{J}$ Swerdlow and others (10 September, p 647). In the abstract lines 16 and 17 should have read, "Have first used ultraviolet beds or lamps more than five years before presentation"; in table I the category for exposure within five years at work and at home should have read $\geqslant 5$ (not $>5)$; and in the discussion, paragraph 3 , the phrase "irradiance causing erythema several times that produced by the summer noon sun" should have read: "irradiance weighted for erythemal effectiveness several times that produced by the summer noon sun." 